УДК 316.354: 351/354 Рубрика ГРНТИ 04.15.07; 04.21. Код ВАКа 22.00.08

Василенко Л.А., докт. социол. наук, профессор, профессор ИГСУ РАНХиГС при Президенте РФ (Москва). E-mail la.vasilenko@ migsu.ru

Применение общественного виртуального ситуационного центра в управлении развитием регионов

Аннотация. Обсуждается создание общественного виртуального ситуационного центра как комплекс информационных технологий для творческой интеграции социологического сообщества в подготовке государственно значимых управленческих решений, их реализации и участии в общественном контроле. Обращается внимание на методологическую основу их взаимодействия - кроссдисциплинарный синтез знаний, фрактально-эволюционная теория естественного упорядочения, которые обусловливают настройку общих «правил игры» и принципов коллективно формировать некий образ идеального, но вполне достижимого будущего (фрактала) как ценностного ядра управляемого объекта.

Обсуждается применение современных управленческих технологий коллективного творчества - краудсорсинг, интерактивные технологии дистанционного взаимодействия групп экспертов в социальных сетях, блогах, мобильные программы (WhatsApp или его аналоги), аналитические комплексы, в том числе программы моделирования и прогнозирования, ГИСы, интерактивные средства проведения социологических исследований (интернет-опросы, системы интернет-голосования с автоматическим формированием массивов данных и средств поддержки их аналитического анализа) и коллективной подготовки докладов и аналитических записок, презентаций (google-таблицы, программы визуализации вариантов решений, Вики-технологии с закреплением авторства). Немаловажным является интегрированность виртуального ситуационного центра с инструментами «Открытого правительства», позволяющего органам власти рассматривать и использовать полученные результаты и предлагаемые решения.

Ключевые слова. социология управления, ситуационные центры, кроссдисциплинарность, фрактал, краудсорсинг, интерактивные технологии коллективного взаимодействия экспертов, общественный контроль, культура открытого управления.

Vasilenko Liudmila, A., Doctor of science (Sociology), professor, The Russian Presidential Academy of National Economy and Public Administration (RANEPA). Moscow. E-mail: vasilenkola@mail.ru

\title{
APPLICATION OF THE PUBLIC VIRTUAL SITUATION CENTER IN THE MANAGEMENT OF THE REGION DEVELOPMENT
}

Annotation. The authors discuss the creation of a public virtual situation center - a complex of information technologies for the creative integration of the scientific community in the preparation of management decisions and participation in public control. The authors draw attention to the methodology of interaction between participants - the cross-disciplinary universal synthesis of knowledge, the fractal-evolutionary theory of natural ordering, which determine the adjustment of the general "rules of the game" and the principles for the collective creation of the image of the future (fractal). 
The authors suggest the use of modern collective management technologies in the virtual situational center, including crowdsourcing, interactive technologies for remote interaction of groups of experts in social networks, blogs, mobile programs (WhatsApp or its analogues), analytical complexes, modeling and forecasting programs, GIS, interactive tools conducting sociological surveys (Internet polls, Internet voting systems with automatic formation of data sets and means of support and their analytica) and collective analytical reports, presentations (google-table, visualization program, Wiki technology). The authors speak about the importance of integrating the virtual situation center with the tools of the "Open Government".

Keywords: sociology of governance, situational centers, cross-disciplinary, fractal, crowdsourcing, interactive technologies of collective interaction of experts, public control, culture of open governance.

Россия, как и многие страны мира вступила в новый этап общественного развития. Происходит переоценка многих истин, ранее казавшиеся незыблемыми. Российская наука, наконец, признала, что развитие общества не является предопределенным, заранее заданным. А.В. Тихонов предполагает, что истоки существующих в современной России проблем в управлении в том, что поиск резервов модернизации системы управления в стране происходит «на основе индустриальной парадигмы, не соответствующей современному движению страны к постиндустриальным ценностям и новым культурным образцам социальной организации» (16, С. 43). Неравновесность становится постоянным атрибутом современного социального порядка в силу вступления в информационную эпоху, когда скорость порождения новых знаний более высока, чем скорость их освоения. Базируясь на теории модернизации, У. Бек обосновывает процесс перехода к эпохе рисков как объективной исторической необходимости, выдвигая идею о необходимости перехода к такой организации общества, в котором действуют механизмы самотрасформации, основанные на самокритичности, эффективном социальном управлении и общественном контроле (1). Н. Луман подчеркивает, что современные общества сталкиваются с нарастанием все большего количества рисков по двум причинам:

- новые знания создают риск идентификации все большего количества негативных последствий сегодняшних решений;

- структурная дифференциация создает все больше уровней принятия решений, что, в свою очередь, усиливает вероятность появления решений с негативными последствиями (рассеивание ответственности за принятое решение) (15, С. 74$)$. 
Этим определяется востребованность коллективного разума экспертов различных регионов России (ученые, специалисты различных профессий, организаторы, государственные деятели) и механизма эффективной общественной экспертизы с целью своевременного «уравновешивания» системы, который позволял бы развивать общество, трансформировать социальный порядок, не допуская социальных взрывов. Одной из форм организации интеллекта общественных независимых экспертов выступает виртуальный ситуационный центр, представляющий собой совокупность виртуальных рабочих мест для аналитиков (независимых экспертов), взаимодействующих при необходимости с представителями органов власти в процессе подготовки решений сложных социальных проблем. Главное - использовать потенциал гражданского общества в лице научных сообществ и аналитиков некоммерческого сектора, поставить всех участников процесса общественного анализа в относительно равные условия, наделив их статусом социальных акторов, субъектов оценки риска и решений, с ним связанных, в отличие от пассивных «воспринимателей» риска. Отметим, что некоторый «всплеск» использования ситуационных центров в государственном управлении приходится на период реализации четырех приоритетных национальных проектов «Здоровье», «Образование», «Доступное и комфортное жилье - гражданам России» и «Развитие АПК». Сегодня же созданная система распределенных ситуационных центров органов государственной власти практически не востребована в силу трудности освоения этих технологий и недостаточной подготовленности руководителей высшего уровня.

Изменение парадигмы взаимодействия участников подготовки управленческих решений является одним из ведущих условий формирования рынка конкурентоспособных интеллектуальных продуктов, достижения сбалансированности интересов участников интеллектуальных креативных процессов. Продуктивное использование столь мощной коммуникационной инфраструктуры и совокупность информационно- аналитических комплексов, обеспечение высокого качества экспертной деятельности может быть достигнуто за счет создания условий, направленных на добровольное принятие «общих правил игры», включая регла- 
ментацию процедур принятия квалифицированных экспертов в состав экспертного сообщества, разработки квалификационных требований к экспертам, регламентацию проведения их общественной аттестации на основе официального рассмотрения представленных экспертных материалов или проведения квалификационного собеседования, направленного на подтверждение профессионализма.

Из участников созданной гражданской экспертной сети станет возможным комплектование эффективных официальных рабочих групп экспертов (выполняющих работу по договору), заинтересованных поддерживать высокий уровень своей квалификации, а также соблюдающих принятые экспертным сообществом этические нормы. Сетевая среда необходима в связи с невозможностью объединить всех заинтересованных общественных экспертов и участников проекта в одном помещении. В связи с большой протяженностью страны наиболее оптимально создание специальной виртуальной сети общественных экспертов и разработка «правил игры», т.е. правил взаимодействий, поведения участников коммуникационного экспертного пространства. Развитие информационных и коммуникационных технологий в рамках синергийного комплекса технологий открытого правительства позволит на государственном уровне создать общественную систему виртуальных ситуационных центров, предназначенную для включения потенциала гражданского экспертного сообщества в социально-экономическое развитие страны.

В то же время участниками гражданской экспертной сети могут быть все желающие (а не только те, кто «допущен» к инновациям с соответствующей оплатой!) - государственные, коммерческие и некоммерческие организации. Особенно важно сохранять и поддерживать открытость данного процесса и предусмотреть возможность принятия и рассмотрения экспертных заключений и замечаний от всех граждан, не являющихся сертифицированными членами экспертного сообщества. В составе виртуального ситуационного центра предлагаются следующие компоненты:

- организация и форматы работы общественных экспертов с использованием технологий коллективного творчества, краудсорсинга и краудфандинга; 
- использование ГИС-технологий, интеграция информационных ресурсов и для использования экспертами Виртуального ситуационного центра

- социологический виртуальный центр с использованием интернет-опросов, социологических флеш-мобов и других методов социологических исследований с автоматическим получением массива данных и средствами интерактивного их анализа, инструментами анализа текстов социальных медиа;

- сетевые комплексы интерактивного моделирования и прогнозирования, коллективного построения распределенных компьютерных моделей с опорой на технологии интеллектуального конвейера мобильных интеллектуальных групп;

- технологии трендспоттинга (обнаружение «ловля» тенденций), мониторинга информационного потока, обнаружение трендов, анализ их динамики и возможного развития, тренд-маппинг (карты трендов), кроссдисциплинарные инструменты: аллоцирование трендов, распределение; определение веса тенденции - менеджмента, построение схем, диаграмм, графиков и т.п. 1;

- технологии подготовки коллективных отчетов, Google-файлы, таблицы, ВИКИ-доклады и т.п.

- подготовка презентаций, средства визуализации, многоэкранные форматы представления вариантов управленческих решений

- включение ресурса в состав Открытого Правительства.

Объединение в сеть реально существующих учебных ситуационных центров ВУЗов России наиболее продуктивен. В них уже имеются подготовленные эксперты, нарабатывается опыт обучения и взаимодействия с различными структурами - ситуационными центрами органов власти и ситуационными комнатами бизнес-структур, центрами стратегической информации. Выделим этапы работы гражданского сообщества в виртуальном ситуационном центре.

Этап 1. Выявление социальных проблем или детализация проблемы, подлежащей коллективному переосмыслению. Сбор информации о событиях большим числом людей и их размещение в сетевой среде (с указанием авторства и контрактных данных эксперта с помощью Интернет технологий.

\footnotetext{
${ }^{1}$ Cм.: What's Next («Что дальше?») снабжает их футурологическими отчетами. URL: Trendhunter.com или Trendspotting.com. Дата обращения 10.09.2017.
} 
Эman 2. Применение трендспоттинга, т.е. проведение отбора, агрегации, анализа, осмысления событий с использованием инструментов по представлению разных точек зрения на происходящие события и факты с целью снятия идеологического влияния на освещение событий, либо четкого обозначения этого влияния. Это позволяет извлекать знания и информацию, большого числа людей («коллективный разум»), собирать и объединять пользовательский контент в виде видео, фото, текста. Информация, полученная от гражданских экспертов первого уровня далее обобщается, анализируется, проверяется, а затем формулируется цель и формализация постановки задач.

Эman 3. Отбор трех - пяти групп специалистов из состава участников второго этапа приступают к реализации сформулированной и поставленной задачи. При необходимости формулируется задание группе по проведению социологических исследований с использованием возможностей той же сетевой среды.

Эman 4. Проведение социологических исследований с использованием самозагружающегося Web-опросника, например, Surveymonkey.com, Anketolog.ru, Testograf.ru, Webanketa.ru, Survio.com. Более полно проведение анкетного онлайн-опроса автоматизируют системы Anketolog.ru, Testograf.ru и Survio.com, имеют возможность создать панель респондентов, реализовать их отбор по заданным параметрам. Другой способ встраивания онлайн-опроса в систему принятия управленческого решения - петищии, на федеральном уровне создана система «Российская общественная инициатива» - коллективное обращение граждан в органы власти с предложением принять определенное решение или нормативный акт (как правило, с приложением проекта). Петиция содержит компонент электронного голосования в виде сбора подписей и возможностью сформулировать аргумент поддержки. Количество подписей граждан с указанием их местожительства (возможно, и других данных) отображается интерактивно (13, С. 33).

Феномен социологического флэшмоба - относительно новый («flash» (англ) - миг, вспышка и «mob» (англ) - толпа, что означает «мгновенная толпа»), известное с 2002 года из работы американского социолога Говарда Рейнгольда, который использует понятие smart mob (англ. умная толпа), понимая под этим 
«своеобразную форму самоструктурирующейся социальной организации с использования коммуникационных технологий» (14). Социологический флэшмоб построен на массовом социологическом действии как культурной массовой акции (опроса, интервью, серии кейс-стади и др.) в ситуации недостатка средств на проведение масштабных социологических исследований (4, С. 457).

Блогосфера и социальные медиа являются кладезью социологической информации. Опыт их исследования стал обширным. В 2012 г. защищена диссертация «Управленческие взаимодействия в социоинформационной блогосфере» (17), комплексный подход к исследованию блогосферы представлен в работе Л.А. Василенко, начиная с формирования подходов к комплектованию информационной базы, на основе сервисных возможностей блого-среды (данных интернет-статистики частоты посещений блогов постоянных пользователей и гостей, уровня их активности в комментариях, анализа тематики общения), выявляя зоны активности, привлекающие наибольшее число участников и оценивая социальную базу исследования. На втором этапе сосредоточивается внимание на разработке инструментария и сборе социологических данных (5, С. 47). Известны социологические работы в области исследования коммуникативного поля управления российской исследовательницы Валентины Шиловой (18) и др.

Эman 5. Анализ информации, интерактивное моделирование и прогнозирование с оценкой рисков и последствий. На основе полученных моделей производится генерация новых идей. Риски инновационного управленческого решения могут оцениваться с точки зрения порождаемых непредусмотренных последствий (по Э. Морену) (8). Отношение к риску определяется прежде всего осознанием возможности влияния в рисковой ситуации с построением правильной системы «отношения к риску» (коммуникативный подход к риску Н. Лумана) (12).

И наконец, еще более продуктивно - оценка возможности вмешиваться в процесс конструирования сложных социальных структур из относительно простых, в процесс их коэволюции, совместного и устойчивого развития. Выгодно развиваться вместе, это приводит к экономии вещественных, энергетических, духовных затрат. Принципы коэволюции могут использоваться для эффективной 
управленческой деятельности, для стратегического видения будущего и планирования на долгосрочную историческую перспективу, для выработки разумной национальной и государственной политики в глобализирующемся мире (8).

Эman 6. Подготовка коллективного доклада с использованием соответствующих средств - google-таблицы, программы визуализации вариантов решений, Вики-технологии или технологий альтернативных вариантов, применяемая в ООН в процессе отчета стран о выполнении ими ратифицированных международных конвенций.

Эman 7. Публичное обсуждение альтернативных докладов, размещенных в сетевой среде с возможностью перепроверки качества аналитики, моделирования, предложенных обоснований.

Эman 8. Виртуальные общественные слушания для выработки коллективного варианта решения с использованием технологий согласования и посредничества (7). Социально ориентированная процедура согласования результатов экспертиз может проходить в процессе виртуальных общественных слушаний по заранее разработанному сценарию. Для этого применяется некоторая формализованное представление результатов экспертизы, чтобы иметь возможность сравнивать позиции и выявлять суть расхождений экспертных мнений. Такая формализация даст основания выработки согласованных конкурирующими сторонами индикаторов и критериев оценки представляемых материалов общественной экспертизы. Разработка средств их визуализации позволит задействовать оборудование ситуационного центра (например, видеостену, средства визуализации) и транслировать эти материалы в виртуальной сети экспертного сообщества.

Эman 9. Построение диалога с представителем Открытого правительства и Общественной палаты для передачи результата в органы власти и организации последующего сопровождения данного процесса.

Эman 10. Представление итогового результата в сетевой среде. Публичное оформление благодарностей особо отличившимся участникам на всех этапах, оплата работы участников, с кем был заключен договор. Публикация материалов в научно-исследовательских журналах и сетевых ресурсах, регистрация исследования в соответствующих базах данных. 
Литература. ция, 2000.

1. Бек У. Общество риска на пути к другому модерну. М.: Прогресс-Тради-

2. Богатых Б.А. Фрактальность и теория функциональных систем // Нелинейный мир», 2008, т.6, № 9, с. $491-499$.

3. Василенко Л.А. Социология в государственном управлении: применение интернет-исследований // Материалы V Всероссийского социологического конгресса «Социология и общество:социальное неравенство и социальная справедливость». 19-21 октября 2016 года. Екатеринбург. [Электр.ресурс]. 2016. С. $8520-8530$.

4. Василенко Л.А. Фрактальный подход к формированию научного и образовательного пространства ЕАЭС // Управленческое консультирование». 2016.№ 11. С. $50-56$

5. Василенко Л.А., Миронова Н.И. Социальная несправедливость: методология социологического измерения и интерпретации // Государственная служба. - 2012. T. 1. - № 1. - С. 47-53.

6. Василенко Л. А., Колесникова Л. А., Писклакова-Паркер М. П. Применение концепции фрактальности к исследованиям деструктивных процессов методами клинической социологии // Человеческий капитал. 2012. № 9. С. $62-67$.

7. Инновационные технологии проведения общественной экспертизы государственно значимых решений и общественных слушаний с применением "высоких" информационных технологий [Василенко Л.А., Гришина Г.Г., Захарова В.И., Калинаева Г.В., Мельникова Т.А., Павлов А.Н., Рыбакова И.Н., Сафонова Т.Е., Сащенко Н.Н., Холин А.Н., Широбокова А.А.] / Под общ. Ред. Л.Василенко, Т.Сафоновой. Москва, 2010. Сер. Инновационные социальные технологии.

8. Князева Е.Н. Взращивать социальные инновации - значит управлять креативно // Материалы Международного форума «Проекты будущего: междисциплинарный подход» 16-19 октября 2006, г. Звенигород.

9. Колесникова Л.А., Степанов А. К. Достижения современной эволюционной теории как естественнонаучная основа исследований инновационных процессов в экономике и обществе // Социология. Естествознание. Общество: сб. науч. статей и мат-лов Всеросс. науч. конф. «Социология и естествознание: междисциплинарные подходы к изучению социальной реальности» $(12-13$ декабря 2014 г., Москва) / Под общ. ред. Н. Е. Покровского. - М.: РОО «Сообщество профессиональных социологов»: ООО «Вариант», 2014. С. 18 - 24.

10. Корнилович В.А. Об использовании прогностических возможностей социологического знания в решении задач стратегического развития российского общества // Гуманитарные науки. вестник финансового университета. 2016. № 3(23). С. 18 - 23.

11. Корнилович В.А., Гайдт А.Ю. «Власть» и «управление» как категории социально- политического знания // Общество: социология, психология, педагогика (2016, № 1. С. 20-25.

12. Луман Н. Решение в 《информационном обществе》 // Проблемы теоретической социологии. Вып. 3..: Межвуз. Сб. /Отв. ред. А.О. Бороноев. - СПб.: Изд-во С.-Петерб. ун-та, 2000. 
13. Модели диалога власти и общества в интернет-коммуникациях. [Василенко Л.А., Василенко В.И., Казанцева О.А., Тарасова Е.В.] Методическое пособие / Под общ. ред. Л. Василенко, Е. Тарасовой. - М., 2015.

14. Рейнгольд Г. Умная толпа: Новая социальная революция / Г. Рейнгольд. - М. : Фаир-пресс, 2006. - 416 с.

15. Риск в социальном пространстве. М., 2001/ Цит. По Шлыкова Е.В. Риск в структуре социально-философского подхода к изучению сущности взаимодействия природы и общества.

16. Тихонов А.В. Теоретико-методологические основы социологии управления как отраслевой научной дисциплины : дис. ... д-ра социол. наук. М., 2000.

17. Шамыкина B.М. Управленческие взаимодействия в социоинформационной блогосфере. Дисс. канд. социол.наук. М., 2012.

18. Шилова В.А. Коммуникативное поле управления: теория, методология, практика. М.: Лотос, 2015. 204 с.

19. Юхно И.В. Флешмоб как современная стратегия политического участия// SCI-ARTICLE.RU. 2014. № 13. 